\title{
Inflammatory bowel disease: impact on scores of quality of life, depression and anxiety in patients attending a tertiary care center in Brazil
}

\author{
Raquel Pellizzari CALIXTO, Cristina FLORES and Carlos Fernando FRANCESCONI
}

Received 14/11/2017

Accepted 16/4/2018

\begin{abstract}
Background - Inflammatory bowel disease frequently affects patients at working age, compromising their quality of life in several levels: physical, psychological, familial and social. Few studies have evaluated the impact of Inflammatory bowel disease on quality of life, anxiety and depression in Brazilian patients. Objective - Evaluate quality of life and its correlation with psychological aspects of patients with inflammatory bowel disease through the Inflammatory Bowel Disease Questionnaire and Hospital Anxiety and Depression Scale. Methods - Cross-sectional study; Inflammatory Bowel Disease Questionnaire, Short Form-36 and Hospital Anxiety and Depression Scale were applied to consecutive outpatients in a tertiary referral center for inflammatory bowel disease. Harvey-Bradshaw Index and Truelove scores were used to evaluate Crohn's disease and ulcerative colitis activity. Sample calculation: 113 patients for a significance level of $5 \%$, power of $90 \%$ and a correlation coefficient of at least 0.3 between scales. Statistical analysis: Student-t test, Pearson and Spearman correlations. Results - One hundred twenty patients participated in the study; mean age: 41.7 years; female: 58.3\%; Crohn's Disease: 69 patients. No low scores for quality of life were found across the four Inflammatory Bowel Disease Questionnaire domains; the Short Form-36 showed low scores in physical limitations (47.2 \pm 42.4 ) and emotional aspects (49.8 \pm 43.4$)$; Hospital Anxiety and Depression Scale score presented a mean of 9.5 \pm 2.7 for anxiety and $8.7 \pm 2.0$ for depression. Quality of life was decreased and Hospital Anxiety and Depression Scale did show increased indices of anxiety and depression, in both diseases only when clinically active. Conclusion - Inflammatory Bowel Disease Questionnaire and Hospital Anxiety and Depression Scale showed that outpatients of a tertiary care center for inflammatory bowel disease in Brazil presented good quality of life. The worst quality of life was associated with the intensity of the disease activity.
\end{abstract}

HEADINGS - Inflammatory bowel disease. Crohn's disease. Ulcerative colitis. Quality of life. Anxiety. Depression.

\section{INTRODUCTION}

Inflammatory bowel disease (IBD), in its both forms - Crohn's disease (CD) and ulcerative colitis (UC) - are chronic illnesses with unpredictable clinical course. Frequently affect young people of a working age, compromising their quality of life (QoL), physical, psychological, familial and social dimensions of life ${ }^{(1-6)}$. A biopsychosocial understanding of illness describes clinical outcome and disease exacerbation as influencing and strongly influenced by both biological and psychosocial factors ${ }^{(7,8)}$.

Studies conducted in other countries have primarily aimed at evaluating the validity, reliability and sensitivity of the quality of life disease-specific instrument, the Inflammatory Bowel Disease Questionnaire (IBDQ), though not being designed to measure the impact of the diseases themselves on the subjects. The influence of disease activity on the association between mood disorders and IBD is unclear ${ }^{(9)}$. Few studies have used the Hospital Anxiety and Depression Scale (HADS) instrument to estimate the influence of these diseases on the psychological aspects of patients (79-12). $^{(9)}$.

There are rare studies that assess the impact of IBD on QoL using a Brazilian population sample ${ }^{(10,13)}$. The knowledge about anxiety, depression and quality of life is an important issue to promote a good care for this patients. This study aimed to assess the impact of IBD on quality of life and the psychological effects of these diseases on patients attending an outpatient tertiary care clinic in southern Brazil and the correlation with disease's activity.

\section{METHODS}

A cross-sectional study was conducted in a population of patients with inflammatory bowel disease, through application of the quality of life assessment tool IBDQ ${ }^{(16)}$ and the Short Form 36 Health Survey (SF-36) ${ }^{(11,12,14-16)}$. Anxiety and depression were evaluated using the Hospital Anxiety and Depression Scale $(\text { HADS })^{(17,18)}$. All versions have been validated for the BrazilianPortuguese language.

\section{Patient selection}

A total of 128 consecutive patients with inflammatory bowel disease were included in the study, all of whom attended an outpatient care clinic at a referral center for the treatment of IBD. All were approached either before or after their routine visit to the clinic and invited to participate in the study.

Declared conflict of interest of all authors: none

Declaration of financial support: Fundo de Incentivo à Pesquisa e Eventos do Hospital de Clínicas de Porto Alegre (FIPE/HCPA).

Programa de Pós-Graduação: Ciências da Gastroenterologia e Hepatologia, Hospital de Clínicas de Porto Alegre, Faculdade de Medicina, Universidade Federal do Rio Grande do Sul, Porto Alegre, RS, Brasil.

Corresponding author: Raquel Pellizzari Calixto. Orcid: 0000-0002-9140-884X. E-mail: raquel_calixto@hotmail.com 


\section{Assessement}

Three questionnaires were applied. The IBDQ, having 32 closed questions with a 7 point response scale, where 1 signifies worst quality of life and 7 equates to the best. The scores were expressed as follows: $\geq 200$ = excellent; $151-199$ = good; $101-150$ = regular and $\leq 100=$ bad. The SF-36, having eleven questions; the scores were coded, summed up and converted onto a scale from 0 to 100 , denoting worst possible to best possible health status, respectively. The HADS questionnaire, having 14 questions divided into two sub-scales to measure anxiety and depression, with classification of scores from 0 (no distress) to 21 (maximum distress).

The questionnaires are considered to be easily understood, self-reported instruments and were completed by patients without any external help.

The clinical indices of UC severity (Truelove) and CD activity (Harvey Bradshaw) were calculated at the clinic on the day of consultation, when the questionnaires were also completed.

\section{Sample size}

The sample size calculation was based on the study of Pontes et al. $(2004)^{(19)}$. For a significance level of $5 \%$, a statistical power of $90 \%$ and a correlation coefficient of at least 0.3 between the scales was used, obtaining a minimum total of 113 patients.

\section{Statistical analysis}

Quantitative variables were described through average and standard deviation, and qualitative variables through absolute and relative frequencies.

The Student t-test was applied to assess the differences between the inflammatory bowel diseases for QoL scores (IBDQ and SF-36) and anxiety and depression scores (HADS).

The relationships between the scales were evaluated using Pearson's correlation coefficient (symmetric distribution) or Spearman's correlation coefficient (asymmetric distribution).

The level of significance adopted was $5 \%(P \leq 0.05)$ and the analyses were performed using SPSS (Statistical Package for the Social Sciences) version 13.0.

\section{Ethical considerations}

The study protocol was approved by the local Research Ethics Committee, and all patients signed a Consent Form.

\section{RESULTS}

Eight patients (6.7\%) from a sample of 128 were excluded due to incorrect completion of questionnaires. The IBDQ was correctly completed by 113 patients, 115 for the SF-36, and 123 for the HADS. From the 120 patients evaluated, $70(58.3 \%)$ were female; the mean $\pm \mathrm{SD}$ age was $41.2 \pm 13$ years; $69(57.5 \%)$ presented with Crohn's disease and $51(42.5 \%)$ with Ulcerative Colitis; $85.7 \%$ of $\mathrm{CD}$ and $64.6 \%$ of UC patients were in remission.

Patient IBDQ scores indicated a good quality of life for all fields of the questionnaire in $62(58.4 \%)$ patients. The best scores were observed in the Functional Capacity and Social Aspects domains, averaging over 65 points. There was no difference observed between the two diseases in any of the domains. (TABLE 1). Lower scores for quality of life were shown in only two of the eight SF-36 domains: the mean $( \pm \mathrm{SD})$ of the Physical Limitations and Emotional Aspects were $47.2 \pm 42.4$ and $49.8 \pm 43.4$, respectively, with both results being below 50 , which is half of the variation from 0 to 100
TABLE 1. Comparison of diseases through the Student t-test for independent samples.

\begin{tabular}{lccc}
\hline Variables & $\begin{array}{c}\mathrm{CD} \\
\text { Average } \pm \mathrm{DP}\end{array}$ & $\begin{array}{c}\mathrm{UC} \\
\text { Average } \pm \mathrm{DP}\end{array}$ & $\boldsymbol{P}$ \\
\hline IBDQ & $\mathrm{n}=68$ & $\mathrm{n}=45$ & \\
Intestinal symptoms & $53.7 \pm 11.1$ & $49.4 \pm 14.6$ & 0.097 \\
Systemic symptoms & $23.8 \pm 6.9$ & $22.6 \pm 7.3$ & 0.371 \\
Social aspects & $26.5 \pm 8.1$ & $25.1 \pm 9.1$ & 0.391 \\
Emotional aspects & $56.9 \pm 17.4$ & $55.5 \pm 19.4$ & 0.696 \\
Total & $160.9 \pm 39.3$ & $152.7 \pm 46.9$ & 0.312 \\
SF- 36 & $\mathrm{n}=61$ & $\mathrm{n}=46$ & \\
Functional capacity & $66.7 \pm 28.5$ & $64.4 \pm 27.6$ & 0.688 \\
Physical limitations & $50.8 \pm 42.6$ & $42.4 \pm 42.1$ & 0.311 \\
Pain & $59.4 \pm 27.1$ & $56.0 \pm 24.8$ & 0.514 \\
General health & $57.1 \pm 10$ & $55.6 \pm 11.8$ & 0.488 \\
Vitality & $56.3 \pm 16.3$ & $52.5 \pm 14.9$ & 0.219 \\
Social aspects & $69.8 \pm 26.5$ & $64.4 \pm 32$ & 0.365 \\
Emotional aspects & $53.3 \pm 43.9$ & $45.2 \pm 42.7$ & 0.343 \\
Mental health & $62.6 \pm 25$ & $57.9 \pm 25.5$ & 0.346 \\
HADS & $\mathrm{n}=67$ & $\mathrm{n}=48$ & \\
Anxiety & $9.3 \pm 2.4$ & $9.8 \pm 3.0$ & 0.296 \\
Depression & $8.4 \pm 1.8$ & $9.1 \pm 2.2$ & 0.094 \\
\hline
\end{tabular}

IBDQ: Inflammatory Bowel Disease Questionnaire. HADS: Hospital Anxiety and Depression Scale.

points. Stratifying patients according to the presence or absence of activity of the disease the QoL is decreased in both diseases when in activity. (TABLE 2).

TABLE 2. Associations between quality of life, anxiety and depression with disease activity.

\begin{tabular}{lccc}
\hline \multirow{2}{*}{ Variables } & Remission & Active & $\boldsymbol{P}$ \\
\cline { 2 - 3 } & $\mathrm{n}(\%)$ & $\mathrm{n}(\%)$ & \\
\hline IBDQ & $\mathrm{n}=83$ & $\mathrm{n}=23$ & $<0.001$ \\
Bad & $5(6.0)$ & $10(43.5)^{*}$ & \\
Regular & $20(24.1)$ & $9(39.1)$ & \\
Good & $37(44.6)^{*}$ & $3(13.0)$ & \\
Excelent & $21(25.3)^{*}$ & $1(4.3)$ & \\
Anxiety & $\mathrm{n}=80$ & $\mathrm{n}=25$ & 0.040 \\
Presence & $40(50.0)$ & $19(76.0)^{*}$ & \\
Absence & $40(50.0)^{*}$ & $6(24.0)$ & \\
Depression & $\mathrm{n}=80$ & $\mathrm{n}=25$ & 0.005 \\
Presence & $36(45.0)$ & $20(80.0)^{*}$ & \\
Absence & $44(55.0)^{*}$ & $5(20.0)$ & \\
\hline
\end{tabular}

IBDQ: Inflammatory Bowel Disease Questionnaire. * Test for a statistically significant association waste adjusted to $5 \%$ significance. 
The HADS questionnaire scores ranged from 0 to 21, and patients presented a mean score of 9.5 for the anxiety and 8.7 for the depression sub-scales, with the median being 9; the minimum points for anxiety and depression were 5 and 2 with the maximum being 16 and 14, respectively. The evaluation in UC population did not detect statistically significant manifestations of anxiety and depression. Indeed, we observed higher levels of depression only in patients with active Crohn's disease. TABLE 3.

TABLE 3. Associations between quality of life, anxiety and depression with the Harvey-Bradshaw Activity Index for Crohn's disease.

\begin{tabular}{lccc}
\hline \multirow{2}{*}{ Variables } & Remission & Activity & $\boldsymbol{P}$ \\
\cline { 2 - 3 } & $\mathrm{n}(\%)$ & $\mathrm{n}(\%)$ & 0.003 \\
IBDQ & $\mathrm{n}=54$ & $\mathrm{~N}=9$ & \\
Bad & $3(5.6)$ & $4(44.4)^{*}$ & \\
Regular & $14(25.9)$ & $3(33.3)$ & \\
Good & $23(42.6)$ & $2(22.2)$ & \\
Excelent & $14(25.9)$ & $0(0.0)$ & \\
Anxiety & $\mathrm{n}=52$ & $\mathrm{n}=9$ & \\
Presence & $27(51.9)$ & $7(77.8)$ & \\
Absence & $25(48.1)$ & $2(22.2)$ & \\
Depression & $\mathrm{n}=52$ & $\mathrm{n}=9$ & \\
Presence & $20(38.5)$ & $9(100)^{*}$ & \\
Absence & $32(61.5)^{*}$ & 0.001 \\
\hline
\end{tabular}

* Test for a statistically significant association waste adjusted to $5 \%$ significance.

When correlated with the Harvey-Bradshaw index for Crohn's disease, an association was found between a greater degree of disease activity and lower quality of life and higher anxiety scores of patients.

There was a statistically significant direct association between the scores for almost all domains of the SF-36 (except general health) with the IBDQ scores, showing a good correlation between both questionnaires. Patients with higher anxiety scores presented lower scores for quality of life on the IBDQ. There was no association between scores of the IBDQ with depression.

There was a statistically significant, inverse association between the Truelove activity index and the SF-36 scores for pain, vitality and mental health, and for all areas of the IBDQ. The same was not observed with the scores from the HADS questionnaire. TABLE 4.

Our date demonstrated that there was no statistically significant association between the physical limitations and general health domains of the SF-36 with the HBI, although all other domains presented with an inverse association. (data not shown).
TABLE 4. Associations between quality of life, anxiety and depression with the severity of Ulcerative Colitis Index (Truelove).

\begin{tabular}{|c|c|c|c|}
\hline Variables & Remission & Activity & $P$ \\
\hline & $\mathrm{n}(\%)$ & $\mathrm{n}(\%)$ & \\
\hline IBDQ & $\mathrm{n}=29$ & $\mathrm{n}=14$ & 0.003 \\
\hline $\mathrm{Bad}$ & $2(6.9)$ & $6(42.9) *$ & \\
\hline Regular & $6(20.7)$ & $6(42.9)$ & \\
\hline Good & $14(48.3)^{*}$ & $1(7.1)$ & \\
\hline Excelent & $7(24.1)$ & $1(7.1)$ & \\
\hline Anxiety & $\mathrm{n}=28$ & $\mathrm{n}=16$ & 0.127 \\
\hline Presence & $13(46.4)$ & $12(75.0)$ & \\
\hline Absence & $15(53.6)$ & $4(25.0)$ & \\
\hline Depression & $\mathrm{n}=28$ & $\mathrm{n}=16$ & 0.661 \\
\hline Presence & $16(57.1)$ & $11(68.8)$ & \\
\hline Absence & 12 (42.9) & $5(31.3)$ & \\
\hline
\end{tabular}

IBDQ: Inflammatory Bowel Disease Questionnaire

\section{DISCUSSION}

Our study showed, rather surprisingly, a low disease impact on quality of life scores for patients with IBD attending the outpatient clinic of a tertiary care referral center in Brazil. Additionally, a low disease impact was also detected on anxiety and depression scores in the same population of patients when their disease is in remission.

This study demonstrated that QoL of CD and UC patients in remission had a better QoL when compared with patients in activity by clinical indices usually applied in clinical settings.

These findings can probably be explained by the high disease remission rates observed in our study, $85.7 \%$ for $\mathrm{CD}$ and $64.6 \%$ for UC. The reason for this is probably related to the fact that our study sample consisted of outpatients, who were interviewed during previously scheduled consultations, whereas patients showing more intense disease activity were more likely to not wait for appointments and to be seen on an off-schedule basis, thus not participating in our study.

Our main objective was to evaluate the impact of inflammatory bowel disease on patient quality of life, using a disease-specific Health-related Quality of Life questionnaire (IBDQ), as well as through generic questionnaires. Our population demonstrated a good quality of life according to the IBDQ, and a lower quality of life in only two areas of the SF-36, physical limitations and emotional aspects. The IBDQ showed that patients presented acceptable scores, with a total mean \pm SD for $\mathrm{CD}$ and UC of $160.9 \pm 39.3$ 
and $152.7 \pm 46.9$, respectively, a result similar who obtained mean scores $( \pm \mathrm{SD})$ of $177.6 \pm 39.6$ for $C D$ and $178.5 \pm 35.3$ for $U C$, but in contrast to IGLESIAS et al. ${ }^{(20)}$ in which patients with CD had lower scores in all domains of the SF-36 and low scores in the Systemic Symptoms section of the IBDQ.

No difference in quality of life was observed between patients with Crohn's disease and those with ulcerative colitis, results also found in other studies using the IBDQ, such as Cohen et.al. ${ }^{(2)}$ who studied 50 patients in southern Brazil, and BLANCO et. al. ${ }^{(21)}$ and Casellas et. al. ${ }^{(22)}$ who assessed the quality of life for 120 and 289 Spanish patients, respectively. In contrast, comparing our study and the above, the finding of Taleban et al. ${ }^{(23)}$, obtained a good correlation of QoL and activity in the disease only to UC using another method of verification of disease activity the "Mayo endoscopic score".

When comparing the IBDQ with the generic SF-36, it was seen that patients showed lower quality of life scores in two domains (Physical Limitations and Emotional Aspects), as also observed by Pontes et. al. (2004) ${ }^{(19)}$. Our study showed an association between all domains of the SF-36 (except general health) with the IBDQ, whereas Pontes found no correlation between the Intestinal Symptoms component of the IBDQ with the SF-36.

Few studies have utilized HADS in IBD patients ${ }^{(24)}$. Our results are similar to the findings of Knowles et al. $(2011)^{(25)}$ who found that when evaluating patients with $\mathrm{CD}, 55 \%$ presented with moderate anxiety and $41 \%$ with moderate depression. Both studies support the idea that keeping patients in remission has a positive impact on their lives, reducing depression levels although our results suggest that there no impact on anxiety.

In the study of Lonnfors et al. ${ }^{(26)}$ Quality of Life was evaluated in 4670 patients in 25 countries starting an online questionnaire developed by EFCCA, European Federation of Crohn's and ulcerative colitis Associations, who demonstrated that patients with IBD had limitations in various situations of life which was also demonstrated in the study by Morandkihani( ${ }^{(27)}$.

Whilst comparing the IBDQ and HADS instruments, no association was demonstrated between the IBDQ domains with the depression sub-scale, Zhang et al. ${ }^{(28)}$ used IBDQ and other tools for analysis of depression and observed a prevalence within this study differently from our study. It is worth noting the consistency of the results: deterioration in QoL and anxiety scores were associated with greater activity of the IBD. The total scores for the HADS correlated with all domains of the IBDQ, particularly so in the area of mental health.

The choice of Truelove and Harvey-Bradshaw indices was determined by the simplicity and ease of data collection, with values only being calculated on the consultation day. The HBI shows good correlation with the Crohn's Disease Activity Index (CDAI) and can replace it without interfering with the quality of the study ${ }^{(6,29-33)}$.

The HBI showed a direct correlation with scores of anxiety and decreased quality of life, as also demonstrated by Pontes et al. ${ }^{(18,19)}$.

Three points can be considered as limitations to our study. A- Questionnaires: the large number of questions to be answered could potentially tire patients; the layout of the SF-36 questionnaire with the use of long tables and many rows and columns could lead to patient confusion and incorrect completion. B- Population sample: patients were evaluated in an elective medical consultation setting, whereas those with greater disease activity were more likely to be seen in the Emergency Room or directly admitted to hospital, therefore not being subject to the questionnaires ${ }^{(34-36)}$. However, this comprised only a small number of cases, with care for almost all patients with IBD attending this institution coming under the control of the authors. Furthermore, whenever necessary, patients with more urgent conditions were promptly scheduled for a regular outpatient visit. As a consequence and with the recruitment period being almost 1 year, these patients were seen by our team in a time span close to the flare-up of their diseases, meaning that any major repercussion on their quality of life would probably not have been missed by our research. C- We did not verify the correlation of quality of life, anxiety and depression with the phenotype of the diseases.

Our study presented significant strengths: a low probability that a sampling bias was responsible for our results as the sample consisted of consecutive patients attending a specialist clinic dedicated to the care of IBD patients at a reference university hospital, part of the state health system; the number of patients evaluated met the study sample size calculation; individuals were evaluated sequentially; the same investigator evaluated all patients; it is the first study to evaluate in a systematic manner anxiety and depression in a population with IBD in Brazil through use of the HADS questionnaire, validated for the Brazilian-Portuguese language; the study showed that all three questionnaires, SF-36, IBDQ and HADS, were sensitive to the health status of patients with IBD, having a good correlation with disease activity indices; the concept that the IBDQ and HADS questionnaires can be considered reliable, easily understood, self-applicable and cost effective, is also supported.

We believe that the incorporation of these questionnaires into our clinical practice will contribute to the assessment of IBD impact on the quality of life of our patients. This broader assessment can, therefore, contribute to a more appropriate and individualized care plan for these patients.

However, it is necessary to conduct further studies in order to evaluate whether IBD in low prevalence countries such as Brazil $^{(37,38)}$, express the same phenotype and severity patterns as in high prevalence countries. If a low incidence of patients with severe disease is found in these countries, it could possibly explain our findings of the low impact on QoL in our IBD patients.

In conclusion, the IBDQ and HADS questionnaires showed that outpatients attending a tertiary care center for IBD in Brazil presented with good quality of life, with no differences being observed between patients with CD and UC. Quality of life for these patients is significantly reduced with increased IBD activity.

\section{ACKNOWLEDGEMENT}

The use of the IBDQ was made under license from McMaster University, Canada.

\section{Authors' contribution}

Calixto RP: scientific, intellectual, conception and design of the study; acquisition, analysis and interpretation of data; statistics analysis; manuscript preparation; critical revision. Flores C: conception and design of the study, critical revision. Francesconi $\mathrm{CF}$ : conception and design of the study, critical revision. 
Calixto RP, Flores C, Francesconi CF. Doença inflamatória do intestino: impacto no score da qualidade de vida, depressão e ansiedade em pacientes atendidos em um centro de atendimento terciário no Brasil. Arq Gastroenterol. 2018,55(3):202-7.

RESUMO - Contexto - A doença inflamatória do intestino afeta frequentemente os pacientes em idade de trabalho, comprometendo a qualidade de vida em vários níveis: físico, psicológico, familiar e social. Poucos estudos avaliaram o impacto da doença inflamatória do intestino na qualidade de vida, ansiedade e depressão em pacientes brasileiros. Objetivo - Avaliar a qualidade de vida e sua correlação com os aspectos psicológicos dos pacientes com doença inflamatória intestinal através do Questionário da Doença Inflamatória do Intestino e da Escala de Ansiedade e Depressão Hospitalar. Métodos - Foi realizado um estudo transversal, com uma amostra de pacientes consecutivos, nos quais foram aplicados os questionários de perguntas fechadas sobre Qualidade de Vida através dos questionários: Inflammatory Bowel Disease Questionnaire, Short Form Health Survey 36; e ansiedade e depressão: Hospital Anxiety and Depression em suas versões validadas para a língua portuguesa praticada no Brasil. Foram aplicados em pacientes ambulatoriais consecutivos em um centro de referência terciária para doença inflamatória intestinal. Os índices Harvey-Bradshaw Index e Truelove foram utilizados para avaliar a doença de Crohn e a atividade da colite ulcerativa. Cálculo da amostra: 113 pacientes para um nível de significância de $5 \%$, força de $90 \%$ e um coeficiente de correlação de pelo menos 0,3 entre as escalas. Análise estatística: teste Student-t, correlações Pearson e Spearman. Resultados - Cento e vinte pacientes participaram do estudo; idade média: 41,7 anos; feminino: 58,3\%; doença de Crohn: 69 pacientes. Não foram encontrados escores baixos para a qualidade de vida nos quatro domínios do questionário da Inflammatory Bowel Disease; O Short-Form-36 mostrou baixa pontuação em limitações físicas $(47,2 \pm 42,4)$ e aspectos emocionais $(49,8 \pm 43,4)$; O índice da escala Hospital Anxiety and Depression apresentou uma média de 9,5 $\pm 2,7$ para ansiedade e 8,7 $\pm 2,0$ para depressão. A qualidade de vida foi diminuída e a Hospital Anxiety and Depression mostrou índices aumentados de ansiedade e depressão, em ambas as doenças somente quando clinicamente ativo. Conclusão - O questionário da Inflammatory Bowel Disease e a Escala de Hospital Anxiety and Depression mostraram que os pacientes ambulatoriais de um centro de cuidados terciários para doença inflamatória do intestino no Brasil apresentaram boa qualidade de vida. A pior qualidade de vida foi associada à intensidade da atividade da doença.

DESCRITORES - Doenças inflamatórias intestinais. Doença de Crohn. Colite ulcerativa. Qualidade de vida. Ansiedade. Depressão.

\section{REFERENCES}

1. Borgaonkar MR, Irvine EJ. Quality of life measurement in gastrointestinal and liver disorders. Gut. 2000;47:444-54.

2. Cohen D, Bin CM, Fayth APT. Assessment of quality of life of patients with Inflammatory bowel disease residing in Southern Brasil. Arq Gastroenterol. 2010:47:285-9.

3. Drossman DA, Patrick DL, Mitchell CM, Zagami EA, Appelbaum MI. Health-related quality of life in inflammatory bowel disease. Functional status and patient worries and concerns. Dig Dis Sci. 1989;34:1379-86.

4. Drossman DA, Creed FH, Olden KW, Svedlund J, Toner BB, Whitehead WE. Psychosocial aspects of the functional gastrointestinal disorders. Gut. 1999;45 (Suppl 2):II25-II30.

5. Krishnan A, Korzeik JR. Inflammatory bowel disease and environmental influences. Gastroenterol Clin North Am. 2002;31:21-39.

6. Ware JE Jr, Sherbourne CD. The MOS 36-item short-form health survey (SF-36): I. Conceptual framework and item selection. Med Care. 1992;30:473-83.

7. Bernklev, T, Moum B, Moum T. Quality of Life in Patients with Inflammatory Bowel Disease: Translation, Data Quality, Scaling Assumptions, Validity, Reliability and Sensitivity to Change of the Norwegian Version of IBDQ. Scand J Gastroenterol. 2002;37:1164-74.

8. Bonaz BL, Bernstein CN. Brain-gut interactions in inflammatory bowel disease Gastroenterology. 2013;144:36-49.

9. Ciccocioppo R, Klersy C, Russo ML, Valli M, Boccaccio V, Imbesi V, et al. Validation of the italian translation of the inflammatory bowel disease questionnaire. Dig Liver Dis. 2011;43:535-41.

10. Hashimoto H, Green J, Iwao Y, Sakurai T, Hibi T, Fukuhara S. Reliability, validity, and responsiveness of the Japanese version of the Inflammatory Bowel Disease Questionnaire. J Gastroenterol. 2003;38:1138-43.

11. Leong RW, Lee YT, Ching JY, Sung JJ. Quality of life in Chinese patients with inflammatory bowel disease: validation of the Chinese translation of the Inflammatory Bowel Disease Questionnaire. Aliment Pharmacol Ther. 2003;17: 711-8.

12. Ren WH, Lai M, Chen Y, Irvine EJ, Zhou YX. Validation of the mainland Chinese version of the Inflammatory Bowel Disease Questionnaire (IBDQ) for ulcerative colitis and Crohn's disease. Inflamm Bowel Dis. 2007;13:903-10.

13. Peyrin-Biroulet L, Cieza A, Sandborn WJ, Coenen M, Chowers Y, Hibi T, et al. Development of the first disability index for inflammatory bowel disease based on the international classification of functioning, disability and health. Gut. 2012;61:241-7.
14. Campolina AG, Ciconelli RM. O SF-36 e o desenvolvimento de novas medidas de avaliação da qualidade de vida. Acta Reumatol. Port. 2008;33:127-33.

15. Ciconelli RM, Ferraz MB, Santos W, Meinão I, Quaresma MR. Tradução para a língua portuguesa e validação do questionário genérico de qualidade de vida SF-36 (Brasil-36). Rev. Bras. Reumatol. 1999;39:143-50.

16. Mitchell A, Guyatt G, Singer J, Irvine EJ, Goodacre R, Tompkins C, et al. Quality of life in patients with inflammatory bowel disease. J Clin Gastroenterol. 1988;10:306-10

17. Botega NJ, Bio MR, Zomignami MA, Garcia Jr. C, Pereira WAB. Transtornos do humor em enfermaria de clínica médica e validação de escala de medida (HADS) de ansiedade e depressão. Rev. Saúde Pública. 1995;29:355-63.

18. Zigmond AS, Snaith RP. The hospital anxiety and depression scale. Acta Psychiatr Scand. 1983;67:361-70.

19. Pontes RMA, Miszputen SJ, Ferreira-Filho OF, Miranda C, Ferraz MB. Qualidade de vida em Pacientes Portadores de Doença Inflamatória Intestinal: tradução para o português e validação do questionário "Inflammatory Bowel Disease Questionnaire" (IBDQ). Arq Gastroenterol. 2004;41:137-43.

20. Iglesias M, Vázquez I, Barreiro-de Acosta M, Figueiras A, Nieto L, Piñeiro M, et al. Health related quality of life in patients with Cohn's disease in remission. Rev Esp Enferm Dig. 2010;102:624-30.

21. Blanco BL, Moreno-Jimenes B, Múgica JMD, Muñoz AR. Relación entre variables sociodemográficas y clínicas y calidad de vida relacionada con la salud en pacientes con enfermedad inflamatoria intestinal. Rev Esp Enferm Dig. 2005;97:887-98.

22. Casellas F, López-Vivancos J, Badia X, Vilaseca J, Malagelada JR. Influence of inflammatory bowel disease on different dimensions of quality of life. Eur $\mathrm{J}$ Gastroenterol Hepatol. 2001;13:567-72.

23. Taleban S, Stewart K, Li D. Clinical Activity and Quality of Life Indices Are Valid Across Ulcerative Colitis But Not Crohn's Disease Phenotypes. Dig Dis Sci. 2016;61:2627-35.

24. Zhang M, Hong L, Zhang T, Lin Y, Zheng S, Zhou X, et al. Illness perceptions and stress: mediators between disease severity and psychological well-being and quality of life among patients with Crohn's disease. Patient Prefer Adherence. 2016;10:2387-96.

25. Knowles SR, Wilson JL, Connell WR, Kamm MA. Preliminary examination of the relations between disease activity, illness perceptions, coping strategies, and psychological morbidity in Crohn's disease guided by the common sense model of illness. Inflamm Bowel Dis. 2011;17:2551-7. 
26. Lönnfors S, Vermeire S, Greco M, Hommes D, Bell C, Avedano L. IBD and health-related quality of life - Discovering the true impact. J Crohns Colitis. 2014;8:1281-6

27. Morandkhani A, Beckman L, Tabibian J. Health-related quality of life in inflammatory bowel disease: Psychosocial, clinical, socioeconomic, and demographic predctors. J Crohns Colitis. 2013;7:467-73.

28. Zhang C, Hewett J, Hemming J. The Influence of Depression on Quality of Life in Patients with Inflammatory Bowel Disease. Inflamm Bowel Dis. 2013;19:1732-9.

29. Best W. Predicting the Crohn Disease Activity Index from Harvey-Bradshaw Index. Inflamm Bowel Dis. 2006;12:304-10.

30. Harvey RF, Bradshaw JM. A simple index of Crohn's disease activity. Lancet. 1980;1:514.

31. Tuelove SC, Witts LJ. Cortisone in ulcerative colitis. Final report on therapeutic trial. Br Med J. 1955;2:1041-8.

32. Vermeire S, Schreiber S, Sandborn WJ, Dubois C, Rutgeerts P. Correlation between the Crohn's disease activity and Harvey-Bradshaw indices in assessing Crohn's disease severity. Clin Gastroenterol Hepatol. 2010;8:357-63.
33. Goodhand JR, Wahed M, Mawdsley JE, Farmer AD, Aziz Q, Rampton DS. Mood disorders in inflammatory bowel disease: relation to diagnosis, disease activity, perceived stress, and other factors. Inflamm Bowel Dis 2012;18:2301-9.

34. Guyatt G, Mitchell A, Irvine EJ, Singer J, Williams N, Goodacre R, Tompkins C. A new measure of health status for clinical trials in inflammatory bowel disease. Gastroenterology. 1989;96:804-10.

35. Irvine EJ. Quality of life of patients with ulcerative colitis: past, present and future. Inflamm Bowel Dis. 2008;14:554-65.

36. Lix LM, Graff LA, Walker JR, Clara I, Rawsthorne P, Rogala L, et al. Longitudinal study of quality of life and psychological functioning for active, fluctuating, and inactive disease patterns in inflammatory bowel disease. Inflamm Bowel Dis. 2008; $14: 1575-84$.

37. Pallis AG, Vlachonikolis IG, Mouza IA. Assessing health- related quality of life in patients with inflammatory bowel disease, in Crete, Grece. BMC Gastroenterology. 2002;2:1.

38. Cosnes J, Gower-Rousseau C, Seksik P, Cortot A. Epidemiology and natural history of inflammatory bowel diseases. Gastroenterology. 2011;140:1785-94. 